\title{
Los Incas como ejemplo de sujeción. El gobierno del Perú y la escritura etnográfica del oidor de Charcas, Juan de Matienzo (1567)
}

\section{The Incas as model of subjection. Gobierno del Perú and the ethnographic writing of the colonial judge of Charcas, Juan de Matienzo (1567)}

Germán Morong Reyes ${ }^{1}$ https://orcid.org/0000-0002-6960-3198

Víctor Brangier Peńailillo ${ }^{2}$ https://orcid.org/0000-0003-3583-2221

${ }^{1}$ Universidad Bernardo O’Higgins, Centro de Estudios Históricos, Fábrica 1990 (Boulevard UBO, Piso 2). Santiago, CHILE. Email: german.morong@ubo.cl

${ }^{2}$ Universidad Bernardo O’Higgins, Centro de Estudios Históricos, Fábrica 1990 (Boulevard

UBO, Piso 2). Santiago, CHILE. Email: vmbrangi@gmail.com

\section{Resumen}

Los estudios andinos, en amplio sentido, han atribuido a Juan de Matienzo -oidor de la Audiencia de Charcas entre 1561 y 1579- la elaboración argumentada de la legitimidad del dominio español, a partir de la consideración jurídica de signar a los Incas de tiranos. Como correlato a esta clásica apreciación historiográfica sobre las sentencias del licenciado, sostenemos que paralelamente a la construcción de una tiranía inca prehispánica, aquel propone un diseño de gobierno que sugiere la recuperación de ciertos aspectos de esta civilización, que facilitaron - por cierto- el control de la fuerza laboral nativa y el disciplinamiento de sus prácticas de vida cotidiana. Una atenta mirada al Gobierno del Perú (1567) advierte que el oidor de Charcas observó la política de sujeción incaica como ejemplificadora, fomentando la rearticulación colonial de algunos de sus aspectos. A partir del análisis de fragmentos textuales de su obra principal, ponemos en evidencia el hecho de que la tiranía fue un ejercicio retórico paralelo a la elaboración de una imagen española del Imperio incaico, en tanto garante de formas modernas de control de la población y disposición de su mano de obra.

Palabras claves: Incas, Perú colonial, indios, sujeción, Charcas.

\begin{abstract}
Andean studies, at large, have attributed to Juan de Matienzo -Colonial Judge of the Real Audiencia of Charcas between 1561 and 1579- the well-argued establishment of the legitimacy of Spanish rule, based on his legal consideration of branding the Incas as tyrants. As counterpart to this classic historiographic appreciation of the verdicts passed by the Colonial Judge, we argue that parallel to the construction of a pre-Hispanic Inca tyranny, he also proposes a government plan suggesting the recovery of certain aspects of this civilization which facilitated -as a matter of fact- the control of the native work force and the disciplining of their daily life. Close scrutiny of Gobierno del Perú (1567) reveals that the Colonial Judge considered the Inca policies of subjection as exemplifying, which encouraged the colonial re-articulation of some of its aspects. From the analysis of some textual fragments of his main work, we expose the fact that tyranny was a rhetorical exercise parallel to the construction of a Spanish image of the Inca Empire, used as guarantor of their modern methods to control the Inca people and ensuring the availability of their work force.
\end{abstract}

Keywords: Incas, Colonial Peru, indians, labor subordination, Charcas.

Recibido: 17 octubre 2016. Aceptado: 19 abril 2017 


\section{Problematización}

En las últimas décadas, el examen a los distintos mecanismos que aseguraron un dominio relativo del aparato administrativo español sobre las sociedades indígenas en el siglo XVI viene cuestionando la clásica posición que ha sostenido que el gobierno virreinal impuso un poder unilateral, desestructurando y socavando al máximo las instituciones indígenas, al imponer sus aparatos de poder específicos sin considerar la experiencia política y sociocultural de los Andes prehispánicos (Stern, 1986; Spalding, 1984; Mumford, 2012; Zuloaga, 2012; Wernke, 2013; Saito et al., 2014). Como acierta Steven Wernke (2014), esta posición hermenéutica concibió la política imperial hispana como la evangelización católica en tanto "proyectos categóricamente incongruentes a lo andino" y, en consecuencia, la respuesta esperable de las sociedades indígenas debía ser un conjunto de prácticas de "resistencia" y conformidad pasiva frente a los dispositivos fiscales de sujeción. A contrapelo, una visión historiográfica y antropológica renovada ha señalado que las peculiaridades en los modos de rehabituación y adaptación a la intervención colonial, por parte de curacas y comunidades enteras, son indicativas de formas diversas de negociación que traslucen una complejidad no reductible a la dicotomía clásica que ha existido al momento de enjuiciar la labor gubernamental de los primeros virreyes. Esta perspectiva crítica y revisionista más contemporánea ha llamado la atención sobre la capacidad de la burocracia virreinal de flexibilizar y adaptar sus dispositivos de exacción fiscal a la experiencia andina, heredera de modos de producción y organización política suficientemente exitosos como para ser desplazados en el corto plazo (Spalding, 1984; Stern, 1986; Mumford, 2012; Zuloaga, 2012; Merluzzi, 2014). Se ha asumido, en síntesis, que la incorporación de las poblaciones andinas al dominio español supuso una diversidad de negociaciones, concesiones y apropiaciones (Ramos, 2016) que complejizan el panorama sociocultural andino colonial, orientando la mirada hacia el análisis de formas variadas en que las autoridades peninsulares y las autoridades étnicas "emularon" (Mumford, 2011; Brading, 2015, p. 162) lo que consideraron valioso y eficiente en el otro. ${ }^{1}$ Este reconocimiento mutuo ha implicado una reconsideración de la noción de etnografía en tanto procedimiento indagatorio de la alteridad, con fines gubernamentales para los hispanos y de "sobrevivencia colonial" para los curacas. El rol jugado por este tipo de indagación -frecuente a partir de 1550 en diversas tipologías textuales- permitió progresivamente a los hispanos aplicar modos de intervención sobre las comunidades indígenas y el territorio (Stoler, 2010).

Los supuestos precedentes nos son necesarios para auscultar con mayor detención una de las obras capitales que traduce el proyecto moderno de gobernabilidad imperial en el centro-sur andino del siglo XVI; se trata del Gobierno del Perí ${ }^{2}$ del oidor de la audiencia de Charcas Juan de Matienzo, obra terminada en agosto de 1567, dirigida a Felipe II y al Consejo de Indias (pero inédita hasta el siglo XX). Una serie de historiadores ha sostenido su utilización pragmática en las decisiones de la conocida Junta Magna de 1568 (Lohmann, 1966; Pérez Fernández, 1988; Julien, 2007; Merluzzi, 2014, p. 127) ${ }^{3}$ y, consecuentemente, en la decisiva influencia políticojurídica que tuvo en las instrucciones y ordenanzas

1 Las recientes investigaciones de Jeremy Ravi Mumford, Marina Zuloaga y Steven Wernke, desde perspectivas globales y locales frente a la reducción toledana respectivamente, comparten un verdadero punto de partida iluminando -en palabras de Wernke- sutiles negociaciones entre las comunidades locales y los órganos del Estado colonial. La sospecha compartida apuntala la metanarrativa de la conquista y permite una orientación metodológica destinada a visibilizar la agencia de las comunidades andinas en la constitución de la sociedad colonial.

2 Se conocen hoy dos copias del manuscrito original, uno en la Biblioteca Apostólica Vaticana (Cod. Barb. Lat. 3585) y otra en la New York Public Library. Existiría otro ejemplar en el British Museum (British Library). Para esta investigación se ha utilizado tanto la copia del manuscrito original existente en la NYPL (MS 74, Obadian Rich collection) como la versión editada por Guillermo Lohmann en 1967.

3 Isacio Pérez (1988) ha sostenido esta vinculación. Según este autor, la obra en comento sería el último informe que llegó del Perú estando el virrey Toledo aún en Espańa y fue entregado a este por Juan de Ovando. El nuevo virrey tendría tiempo suficiente para leer a Matienzo y analizar sus propuestas (entre fines de 1567 y marzo de 1569). Manfredi Merluzzi (2014) y Esperanza Mo Romero (2000) asumen también esta posición. 
toledanas, años más tarde (Mo Romero, 2000, p. 334; Merluzzi, 2014, p. 128). Juan de Matienzo fue considerado en las decisiones gubernamentales vinculadas a aspectos tributarios, regulación de las visitas a las comunidades, la política de reducciones y, sobre todo, a la organización de la vida andina en dos repúblicas (de indios y españoles). En este sentido, Lohmann Villena señaló ciertas concordancias entre muchos pasajes de la Instrucción general, extendida a los visitadores por Francisco de Toledo el 16 de junio de 1571, con la reglamentación propuesta por el magistrado (Lohmann, 1966). Es más, el virrey habría considerado el uso de los quipus para inventariar el ganado de la comunidad y la concienzuda planificación urbana que imponía su política reduccional (Cummins, 2002; MacCormack, 2006; Curatola y De la Puente, 2013).

No cabe la menor duda de que Toledo haya incorporado a Matienzo en el equipo de sus consejeros y ayudantes. Ha sido reputado, además, como un perspicaz y eficiente letrado ${ }^{4}$ con gran experiencia de relator en la Cancillería de Valladolid antes de pasar al Perú en 1560, lugar frecuentado por los miembros más conspicuos de la Corte Real (Lohmann, 1966; Aranda, 2005, p. 9). Su diseño político-administrativo y la elaboración de un tejido legal al servicio del control estatal de las fuerzas productivas coloniales, con fines de su eficiencia o "aprovechamiento", su ordenada tasación tributaria y el interés mostrado por conocer a las sociedades andinas para gobernarlas "adecuadamente" convierten al Gobierno del Perú en un escrito interesante y desafiante a la vez, complejo y de gran espesor (Presta, 2008, pp. 396-400).

Dentro de las múltiples posibilidades hermenéuticas que permite esta obra, hemos optado por analizar -a partir de una selección de fragmentos textuales de su tratado capital- la descripción política

4 Esta categoría agrupa a los juristas, licenciados y burócratas en la España moderna y describe una serie de realidades sociológicas que pueden ser englobadas en la denominación de profesionales del saber, que integraron la administración en la Monarquía hispánica. El común denominador de estos elementos sociales, siempre minoritarios, parece radicar en el hecho de tener una formación universitaria en los centros más prestigiosos de su tiempo: Valladolid o Salamanca (Aranda, 2005). y gubernamental que efectúa de los incas, sobre la base de dos argumentaciones que se desarrollan de forma complementaria a lo largo de varios capítulos contenidos en la primera parte, dedicada a la "República de los indios". En el ámbito políticojurídico, el Gobierno del Perú se propuso legitimar la conquista española (Pereña et al., 1982, p. 45) frente a una bullada crítica pro lascasiana, sosteniendo el carácter tiránico del Imperio incaico a partir de un cúmulo de fuentes de autoridad (Aristóteles, Platón, Séneca y Santo Tomás). Por otra parte, en un ámbito de sujeción tributario-laboral propuso, paralelamente a los intereses ideológicos específicos, un mantenimiento colonial de ciertas prácticas prehispánicas tendientes al control tributario y laboral (por ejemplo, la reformulación colonial del tocuirico, el mantenimiento del quipu, la reinstalación de los chasquis, entre otras). Siguiendo este razonamiento, sostenemos que a pesar de que este burócrata polemizaba con fruición sobre la legalidad de forzar a los indios al trabajo obligatorio, compartía con clérigos y cronistas una visión pragmática sobre los Incas como buenos gobernantes en términos de ejercer la vigilancia y el control-, ${ }^{5}$ manteniendo un orden prehispánico en policía. ${ }^{6}$

5 Jeremy Ravi Mumford ha desarrollado largamente esta afirmación. En su Vertical Empire, obra dedicada a estudiar el proceso de reducción llevado a cabo por Francisco de Toledo (1569-1581), muestra la necesidad del gobierno virreinal de mantener dentro de lo posible los mecanismos que aseguraron a los Incas un control eficiente de los recursos productivos, con fines de asegurar el proyecto político colonial. Al interior de este modelo -como puede apreciarse en sus investigaciones- la práctica etnográfica, es decir, conocer en profundidad la cultura del otro, sirvió para sustentar la idea de recuperar una imagen espańola del Imperio inca (Saito et al., 2014; Mumford, 2012, pp. 126-127).

6 Debe recordarse que la noción de policía, extensamente desarrollada por Michel Foucault en Seguridad, Territorio, Población (2006), contiene una multiplicidad de sentidos, pero todos ellos ciertamente vinculados a las llamadas "tecnologías de gobierno" (por lo menos entre los siglos XV-XVI). La noción de policía, siguiendo este razonamiento y considerando el texto de Matienzo, implica el conjunto de los mecanismos por medio de los cuales se asegura el orden, el crecimiento canalizado de las riquezas y las condiciones de mantenimiento de la salud en general. También se denomina policía, siempre sin movernos de los siglos XV y XVI, al conjunto de los actos que van a regir precisamente a las comunidades bajo la autoridad pública. 
Problematizamos, en adelante, la argumentación que presenta a los Incas como tiranos y como referencia de sujeción laboral a la vez, en una relación que parece no ser excluyente si se comprende la lógica con que era formulado el ejercicio de la tiranía en el siglo XVI (Duviols, 1982; Mumford, 2011). Creemos que esta descripción instrumental de los Incas es parte de un proyecto gubernamental en un contexto histórico de ardua discusión jurídica, en que el "conocimiento empírico" y la "razón de Estado" se vincularon con los modos de intervención sobre las poblaciones y los territorios colonizados (Foucault, 2006; Brendecke, 2012).

\section{Autoridad etnográfica o conocimiento de las costumbres de los naturales}

No ha sido común en la historia y etnohistoria andinas atribuir a Juan de Matienzo la labor de un asiduo etnógrafo (Solodkow, 2014; Marzal, 1993), ${ }^{7}$ preocupado de "conocer" y entender -con un sentido altamente pragmático- los principios rectores básicos que aseguraron gobernabilidad a los Incas y a sus intermediarios, los curacas. Se ha puesto atención, más bien, a las formulaciones jurídicas que imputan a estos últimos prácticas tiránicas deleznables -en oposición a la observación de clérigos- y a la prolija descripción del plan reduccional (Cummins, 2002; MacCormack, 2006, p. 119; Mumford, 2012; Merluzzi, 2014, p. 126). Con el argumento de que el licenciado vallisoletano fue un ardiente defensor del derecho de conquista, un despreciador de la cultura

7 Entendemos aquí la noción de etnografía en un sentido amplio. Si se considera su etimología griega ethnos (pueblo) y grapho (trazo escritura), tenemos una práctica de "escribir un pueblo, definirlo y catalogarlo para representarlo en un espacio discursivo" (Solodkow, 2014, pp. 19-20). Eso fue precisamente lo que hicieron los letrados colonialistas; describieron al "otro" para traducirlo y procurar un sustento epistemológico clave para la dominación colonial. Para Mumford (2012) los colonizadores de la primera modernidad escribieron sobre los pueblos no occidentales y naturalizaron una práctica escritural sobre el otro con vistas a conseguir un gobierno y evangelización sólidos. Al igual que el colonialismo tardío del siglo XIX, el propio del siglo XVI procuró el desarrollo de una indagación del otro para su sujeción (Saito et al., 2014, p. 131). andina y acérrimo enemigo de los curacas, la historiografía del Perú colonial ha situado su ideología política en el proyecto centralizador y hegemónico de Felipe II y, particularmente, ha sentenciado su proyecto político como "antiindigenista". ${ }^{8} \mathrm{Si}$ bien no pueden ser soslayadas las afirmaciones precedentes, es importante anotar que la escritura política del oidor de Charcas es más compleja que una reducción generalizadora hacia el lado "hispanófilo". La atenta observación sobre la cultura andina y el conocimiento demostrado acerca de los mecanismos sociopolíticos de sujeción -operado por el Inca y los curacas-, en muchos pasajes del Gobierno del Perú, son indicativos de un conocimiento pragmático con fines de legitimar un proyecto de gobernabilidad. No se trataría de un sentido "indigenista" -como ha sido sostenido para la pluma de Polo Ondegardo (Pujana, 1977)- sino de argumentar, sobre la base de un saber fundado en lo empírico, la necesidad burocrática de mantener ciertos dispositivos de control al interior de una lógica andina de poder. Ha sido J. R. Mumford (2012) el que ha precisado que el plan de su tratado apuntó, de cierto modo, al "aprendizaje" y recuperación de los mecanismos incaicos de sujeción, como fue la sugerencia de reinstalar al tocuirico y de imitar las disposiciones tributarias y laborales dispuestas con asombroso pragmatismo por los Incas, en función del "conocimiento" que tuvieron de sus gobernados. ${ }^{9}$

Es importante recordar que el Gobierno del Perú fue escrito al interior de un período de álgida producción textual (1550-1570), mayormente vinculada a la legitimidad de la conquista española y a la fuerte controversia sobre la disposición de la mano de obra indígena, en un contexto crítico para la hacienda real (Bakewell, 1989; Merluzzi, 2014; Stern, 1986; Pérez Fernández, 1988). ${ }^{10}$ Como agravante, además,

8 Comparando su descripción del indio con la argumentación aristotélica de Ginés de Sepúlveda en su Democrates Segundo (1547). A estas alturas, es evidente el hecho de que la comunidad de discurso entre ambos personajes responde a la legitimidad que adquirió en el período la doctrina aristotélica de la "servidumbre natural".

9 No obstante, no desarrolla con mayor especificidad estas afirmaciones.

10 El Gobierno del Perú fue redactado bajo la administración de Lope García de Castro (1564-1569), presidente de la Audiencia de Lima. Peter Bakewell (1989) atribuye 
se desarrolló una dura discusión entre el clero regular, los curacas y la burocracia letrada, en torno a la bullada polémica que suscitó el problema de la perpetuidad de las encomiendas, a partir de 1554 (Bakewell, 1989). Esta situación gatilló la circulación de una serie de textos de carácter indagatorio, ordenados por la Corona a través de cédulas e instrucciones destinadas a proveer de información empírica a la autoridad metropolitana.

A partir de 1550 y de forma progresiva figuran las primeras relaciones, visitas e informes ${ }^{11}$ tipologías textuales que van configurando un impulso etnográfico -en tanto herramienta para la sujeción colonial-, volviendo a los indios más 'legibles' y, por lo tanto, más gobernables. Este impulso, gatillado por la expansión colonialista del siglo XVI, permitió a la postre adecuar los mecanismos e instituciones coloniales a las realidades sociopolíticas andinas sobrevivientes hacia 1560 (Colajanni, 2004; Marzal, 1993). Esta última afirmación está presente en las descripciones etnográficas de Polo Ondegardo (1561 y 1571) y Juan de Matienzo (1562 y 1567) y en muchos otros agentes coloniales, clérigos y burócratas, preocupados en extremo de indagar sobre los indios y los Incas para fines ideológicos específicos. Al unísono, se conformaba una cultura del conocimiento empírico -al servicio del colonialismo-, que gozó de autoridad moral en la metrópoli (Brendecke, 2012).

La relación estratégica entre empiria y producción de saber, para fundamentar modos de intervención gubernamental sobre la población dominada, permite comprender que un tipo de escritura que signamos de etnográfica se sustenta en la convicción de que esta pone en juego una estrategia de

a este licenciado ser el artífice -prosiguiendo los objetivos del Conde de Nieva (1561-1564) - de la consolidación del poder real en el Perú. Su intervención mayor se traduce en la creación del cargo de corregidor de indios (1565), agente real que debilitaría la relación de abuso entre los indios del común y sus autoridades directas; curacas, religiosos y encomenderos.

11 Por estos años, se producen un cúmulo de informes, relaciones y pareceres, entre ellos, Damián de la Bandera (1557), Cristóbal de Castro y Diego Ortega Morejón (1558), Hernando de Santillán (1563), Polo Ondegardo (1561,1571), Francisco Falcón (1567), Lópe de Atienza (1571), Bartolomé de la Vega (1562), Cristóbal de Molina, "el almagrista" (1553), entre otros. autoridad específica. Esta estrategia ha involucrado la pretensión no cuestionada de aparecer como la que proporciona la verdad de un texto (Clifford, 2001). Este principio -visible en los documentos mencionados- puede sustentar la idea de que la experiencia de los letrados (ergo, lo "visto", lo "conocido") se transformó en relato escrito autorizado y que sus informaciones fueron concebidas como una versión adecuada de la "realidad" en las esferas metropolitanas.

La obra de Juan de Matienzo sugiere la existencia de una pretensión etnográfica justificada sobre la necesidad de administración y control de los indios, en tanto factores indispensables para la producción agrícola y minera. La declaración sobre la legitimidad de un saber producido in situ figura en dos contextos discursivos específicos al interior de la obra; en la primera parte, en que describe la naturaleza y complexión de los indios y, en la segunda, en que define las características del buen gobernante (Matienzo, 1967 [1567], I, pp. 3, 16-19 y II, p. 201). En ambos contextos, el conocimiento de la realidad descrita es homólogo a las virtudes del buen gobierno; en tanto, la autoridad epistemológica de estas sentencias deviene del uso estratégico que le da a la tradición clásica. Una lectura detenida a la declaración de propósitos del tratado en comento sugiere una preocupación sistemática del licenciado por manejar y procesar información de primera mano, derivada de la observación en el espacio virreinal que le tocó recorrer y administrar desde su llegada al Perú en 1561, desde Lima a Potosí. Los ejemplos brindados para esta suerte de argumentación política pretenden legitimar un tipo de funcionario cauto, letrado y perspicaz en el manejo de una etnografía autoconsciente:

Para lo que adelante se dirá, hay necesidad de saber la condición y natural inclinación de los indios, porque mal puede gobernar el que no conoce la condición de los que han de ser gobernados, ni menos corregir las costumbres de los que no conoce (Matienzo, 1730? [1567], fol. 15v-16r y 1967, p. 16);

Otra cosa ha también de guardar el que gobernare esta tierra: que no entre de presto a 
mudar las costumbres y hacer nuevas leyes y ordenanzas, hasta conocer muy bien las condiciones y costumbres de los naturales de la tierra y de los españoles que en ella habitan (Matienzo, 1730? [1567], fol. 167r y 1967, p. 201);

[...] aunque estoy informado de munchas cosas de aquella tierra, no quiero tratar de ella más de lo que tengo apuntado, porque no la he visto ni estado en ella, y será hablar de oidas (Matienzo, 1730? [1567], fol. 215r y 1967, p. 248);

[...] pero como no es mi intento tratar del Perú que he visto y pisado, no trataré de esto (Matienzo, 1730? [1567], fol. 222v y 1967, p. 255$).{ }^{12}$

En 1562, en su "Parecer cerca de la perpetuidad y buen gobierno de los indios del Peru y aviso de lo que deven hazer los encomenderos para salvarse" (Pereña, 1982), ${ }^{13}$ Matienzo argumentaba ser los "ojos" del rey, naturalizando una práctica sistemática por parte de la burócratas y clérigo: "será bien que los que en aquellos reynos hemos estado y visto por vista de ojos la necesidad que de lo sobredicho tienen, sirvamos de ojos a nuestro Rey y Señor, que es V. Mag., para que con los nuestros vea lo que con su Real preferencia ver no puede" (Matienzo, 1982 [1562], p. 614). ${ }^{14}$

Siguiendo esta argumentación, el licenciado "observará" los vestigios de una política cusqueña que ajustaba su práctica a dos elementos sustantivos: el conocimiento asiduo de los otros y la flexibilidad de sus aparatos de sujeción sobre poblaciones y espacios diversos. Más allá de la especulación teórica sobre el carácter tiránico de los Incas -lo que justificaba la legalidad de la conquista y la caída del reducto de Vilcabamba-, la realidad del espacio virreinal evidenciaba la necesidad de perpetuar mecanismos de compulsión prehispánicos en estricta coherencia

12 Las cursivas son nuestras.

13 El texto en comento fue publicado por Luciano Pereńa en 1982. El manuscrito original lleva la signatura AGI, Indiferente 1530, ff. 58r-75r.

14 Las cursivas son nuestras. con el sustrato cultural andino y con sus intrincados y diversos espacios de habitación (Stern, 1986 [1982]; Mumford, 2012). Desde esta posición, la de un diestro y perspicaz observador, es que su escritura manifiesta reiteradamente una combinación entre justificación política y pragmatismo; el mantenimiento de algunas "leyes del Inca" sin desatender la comprobación de una flagrante y "cruel" tiranía.

\section{La construcción del orden tiránico: los Incas y la legitimidad de la conquista}

Hacia 1570, la construcción de la tiranía incaica constituía una herencia escritural derivada de los relatos de los primeros conquistadores, proclive a la justificación y legitimación de la conquista española. Tema que ha recibido tratamiento sistemático por variados investigadores desde ángulos analíticos diversos (Duviols, 1982; Millones Figueroa, 1998; Mumford, 2012 y 2011; Vacarella, 2007; Loza, 2002; Parra, 2015). El asesinato del Inca Atahualpa, en julio de 1533, obligó a Francisco Pizarro y a un grupo de cronistas a construir el primer relato de este gobernante como tirano, justificando un tiranicidio (Duviols, 1982). ${ }^{15}$ Esta asignación se oponía al "señorío natural", situación política reconocida como legítima en el sentido que derivaba de una "ley natural", universalmente aceptada. El "señor natural”, sinónimo en un ámbito político de justicia, orden y bien común, fundaba su poder tanto en la elección (derecho visigodo) como en el contrato que lo une en juramento a la comunidad (contratus subjectionis) (Duviols, 1982). ${ }^{16} \mathrm{Al}$ contrario, el tirano

15 El corpus textual que organiza una primera descripción de Atahualpa como tirano estaría ejemplificado en las obras de Hernando Pizarro (1533), Francisco de Xerez (1534) y la conocida "letra" del ayuntamiento de Jauja (1534) (Duviols, 1982).

16 Las nociones de señor o señorío natural devenían de una larga tradición filosófico-política-jurídica, en la cual podemos inscribir a Aristóteles (Política); Jean de Salisbury (Polícratus, 1159), Santo Tomás (Somme, De Regno) y el corpus legal visigodo (Fuero Juzgo) (Duviols, 1982; Mumford, 2011). Bajo la exégesis de los textos precedentes, el señor natural debía reunir las siguientes condiciones: descender de una línea noble a partir de un fundador elegido por la comunidad; ser aceptado por todos como señor (vasallos); respetar los tratados; 
subvertía los valores y las prácticas políticas precedentes; usurpar el poder por la violencia en contra de la voluntad de la comunidad, mantener su poder a través de mecanismos crueles e injustos, no respetar acuerdos ni tratados, ser un traidor, conquistar a otros pueblos mediante la violencia y la imposición de la fuerza, ser un agresor. Estas descripciones pueden ser colegidas también en las Siete Partidas de Alfonso el Sabio (1807, Tomo II, pp. 10-11) $)^{17}$ y, probablemente, fue este tratado el que junto a la Política de Aristóteles ${ }^{18}$ constituían las vigas maestras como fuentes autorizadas para la burocracia virreinal, ávida de justificar la conquista y desacreditar, al unísono, la prosa de los clérigos lascasianos (sobre todo entre 1550 y 1570). ${ }^{19}$ Pierre Duviols señala que la noción de tiranía imputada a los Incas fue elaborada a lo largo del siglo XVI peruano con distintos móviles políticos, en circunstancias históricas precisas. Para los hermanos Pizarro y sus cronistas, la imputación de tal categoría, en términos de definir el gobierno de Atahualpa, se sustentó en la justificación de un tiranicidio, en el supuesto de que este gobernante habría usurpado el poder, habría actuado contra Dios, los cristianos y sus propios vasallos, de forma agresiva y violenta. Los términos que expresaban esta práctica gubernamental eran la opresión, el despotismo, la perfidia y la traición (Duviols, 1982), en tanto que para Francisco de Toledo, 39 años más tarde,$^{20}$ el móvil y uso de la condición de tirano transitaba por el argumento de reducir los vestigios tambaleantes de la nobleza cusqueña en Vilcabamba, proveer a la Corona de un justo título de conquista sobre la base de un levantamiento de información in situ ("demostrar" con "evidencia" la tiranía incaica) y, luego, justificar el descabezamiento del joven Inca Tupac Amaru en 1572. Este últi-

no declarar la guerra en conformidad a la razón y la justicia; promover el bien de sus vasallos, y defender la fe católica.

17 Siete Partidas, título I, ley IX y X.

18 La Politica, libro VIII, capítulo IX.

19 Para una discusión pormenorizada de esta polémica, ver Pérez Fernández $(1988,1995)$.

20 Según Duviols (1982, p. 17), la década de 1550 invoca nuevos antecedentes a los atributos tiránicos de Atahualpa en la pluma de los cronistas López de Gómara (1552), Agustín de Zárate (1555) y Pedro Cieza de León (1553). Por ejemplo, el asesinato (fraticidio) de Huáscar, legítimo heredero al trono según las reglas de sucesión europeas, elementos característicos de un tirano. mo acto respondía a la preocupación del virrey por evitar una restitución del incario, acción alimentada por varios frailes dominicos. El interés por gobernar sin contrapeso político e imponer orden y policía llevaron a Toledo a iniciar una campaña con un fuerte componente ideológico antiinca, reflejada con claridad en sus famosas Informaciones (Levillier, 1940; Merluzzi, 2007). ${ }^{21}$

Asimismo, la escritura del Gobierno del Perú puede ser inscrita en una larga discusión político-jurídica (1550-1575) cuya tensión gravitaba sobre la consideración de nominar a los Incas como "señores naturales" o bien como "tiranos" (Millones, 1998). La historiografía del Perú colonial ha centrado su interés mayormente en el corpus toledano, al interior del cual se comprenden las prácticas tiránicas de aquellos, a la luz de una exégesis intencionada sobre los textos clásicos y escolásticos (Mumford, 2011). En este corpus, el Parecer de Yucay (atribuido al dominico García de Toledo, 1571) y la Historia General Llamada Índica (1572) de Pedro Sarmiento de Gamboa están indisolublemente unidas por imputar a los cusqueńos una "cruel y envejecida tiranía" y por la necesidad de contrarrestar los argumentos de Bartolomé de Las Casas en relación a los derechos de conquista (Kermele, 2011; Bauer y Decoster, 2007; Castro Klaren, 2001; Vacarella, 2007; Mumford, 2011). No ha sido asumida explícitamente la relación del Gobierno del Perú con las obras precedentes y no sabemos aún si Sarmiento de Gamboa o García de Toledo consultaron la obra axial del oidor ${ }^{22}$ considerando, en estricto rigor, que fue Matienzo uno de los primeros burócratas que define las prácticas tiránicas a la luz de la tradición clásica (a partir de referencias autorales y analogías precisas). Sin embargo, su retórica antiinca antecede a los propósitos políticos concretos de la justificación jurídica toledana y se inserta en un contexto mayor definido por la controversia jurídica y moral de legitimar la

21 No obstante, J.R. Mumford ha sostenido que el virrey admiraba a los incas y replicó con lógicas hispanas sus sistemas de poder (Mumford, 2011 y 2012).

22 Ha sido Sara Castro-Klaren (2001) la única que se ha permitido -sin mayor argumentación- vincular al licenciado con las obras en comento. Se ha asumido que Sarmiento de Gamboa habría utilizado el Parecer de Yucay para la redacción de su Historia General (Mumford, 2011). 
conquista e impugnar las tesis del "señorío natural" de los Incas. Este móvil discursivo, al parecer, contradice las argumentaciones lascasianas vertidas en el Tratado de las doce dudas (1564); texto elaborado con una serie de informaciones recogidas in situ por el dominico Bartolomé de la Vega en su Memorial de agravios, presentado al Consejo de Indias en 1561 (Julien, 2007).

La construcción de la tiranía incaica, visible en el primer capítulo de la primera parte y, consecuentemente justificada en los capítulos dos y tres ${ }^{23}$ responde, a nuestro juicio, a una elaboración que implica dos dimensiones fundamentales: a) Se trata de un ejercicio de discusión jurídica, probablemente a petición de la autoridad virreinal para contrarrestar la furia discursiva de los seguidores del obispo de Chiapas, ${ }^{24}$ proclives a una restitución del "señorío" inca en la década de 1560 y, b) Que esta construcción se ampara paralelamente en dos campos de referencia de importancia: por un lado, el saber clásico (Aristóteles, Platón y Séneca) en tanto autoridad hegemónica que define la naturaleza misma de la tiranía y, por otro, las descripciones sobre el gobierno incaico que proporciona la cronística hispana producida en la década de 1550. Lohmann advierte, en las notas aclaratorias a la edición de $1967,{ }^{25}$ la transcripción de un párrafo completo del capítulo XXXVIII de la Crónica del Perú (primera parte) ${ }^{26}$

23 Cfr. capítulo I, "Del gobierno y tiranía de los Ingas, y cómo no eran reyes naturales de estos Reinos del Perú" (Fol. 6v-11v); capítulo II, "De cómo entraron los espańoles en este Reino, y como fue justamente ganado y tiene su magestad justo título a él” (Fol. 11v-14v); capítulo III, "Del contento que los indios tienen del buen tratamiento que agora se les hace por los espańoles y del gran cuidado que de ello tienen las Audiencias por mandado de su Magestad" (14v-15v).

24 Isacio Pérez Fernández (1988) aventura la hipótesis de que el Gobierno del Perú fue encargado por Lope García de Castro a Matienzo para obtener un parecer sobre el trabajo indígena y la legitimidad de la conquista. Asimismo, el presidente de la Audiencia de Lima habría encargado otro al licenciado Falcón para obtener una opinión contraria a la presentada por el oidor. El parecer de Falcón habría sido expuesto en el segundo Concilio Limense.

25 Cfr. Lohmann (1967).

26 Conocida de forma general como "Parte primera de la crónica del Perú que trata de la demarcación de sus provincias: la descripción de ellas. Las fundaciones de las de Pedro Cieza de León (1553). Esta transcripción se permitió una omisión intencional de ciertos párrafos que podrían haber sido contradictorios con la intención programada de atribuir la tiranía como ejercicio político en los Incas. Las referencias a este autor, además, figuran de forma explícita al momento de describir y admirarse por las construcciones monumentales desarrolladas por estos últimos. ${ }^{27}$ Por ello, la autoridad de sus proposiciones se asienta en dos corpus de información ponderados, según la naturaleza de sus relatos; las fuentes clásicas (a partir de las cuales asemeja las prácticas políticas de los Incas con los tiranos del mundo grecolatino) y la crónica de Cieza, probablemente valorada por contener información obtenida in situ y ser la primera descripción histórica impresa sobre los incas (Julien, 2000).

$\mathrm{Al}$ analizar con cuidado el capítulo I de la primera parte, el objetivo central de la apertura es presentado como una "necesidad de presuponer quiénes fueron los Ingas, y de la manera que en general de su gobierno" (Matienzo, 1730? [1567], fol. 6v y 1967 , p. 6). Para ello, declara su fuente de primera mano; "diré lo que, por relación de los indios del Cuzco antiguos, sabemos". Tras esta declaración indagatoria, el capítulo sigue con una escueta explicación histórica tomada de la crónica de Pedro Cieza de León:

nuevas ciudades. Los ritos y costumbres de los indios. Y otras cosas extrañas dignas de ser sabidas. Hecha por Pedro de Cieza de León, vecino de Sevilla" (Cieza de León, 2005 [1553], p. 5).

27 Cfr. Matienzo (1730? [1567], fol. 10v y 1967, p. 8). 


\begin{tabular}{|c|c|}
\hline $\begin{array}{l}\text { Pedro Cieza de León. Crónica del Perú, } 2005 \text { [1553], } \\
\text { pp. 109-110 }\end{array}$ & $\begin{array}{l}\text { Juan de Matienzo. Gobierno del Perú, } \\
1967[1567] \text {, pp. 6-7 }\end{array}$ \\
\hline $\begin{array}{l}\text { "Estando de esta suerte todas las provincias del Perú, se } \\
\text { levantaron dos hermanos, que el uno de ellos habría por } \\
\text { nombre Mango Capa. De los cuales cuentan grandes } \\
\text { maravillas los indios y fábulas muy donosas [...] Este Mango } \\
\text { Capa fundó la ciudad del Cuzco, estableció leyes a su usanza. Y } \\
\text { él y sus descendientes se llamaron Ingas, cuyo nombre quiere } \\
\text { decir o significa reyes o grandes señores. Pudiendo tanto, } \\
\text { que conquistaron y seńorearon desde Pasto hasta Chile, y sus } \\
\text { banderas vieron por la parte del Sur al río de Maule, y por la } \\
\text { del Norte al río de Angasmayo, y estos ríos fueron término } \\
\text { de su imperio, que fue tan grande que hay de una parte a } \\
\text { otra más de mil y trescientas leguas. Y edificaron grandes } \\
\text { fortalezas y aposentos fuertes, y en todas las provincias tenían } \\
\text { puestos capitanes y gobernadores [...] Hicieron grandes cosas, } \\
\text { y tuvieron tan buena gobernación, que pocos en el mundo } \\
\text { les hicieron ventaja [...] y al Sol tenían por dios soberano, } \\
\text { al cual hicieron grandes templos. Y engañados del demonio } \\
\text { adoraban en árboles y en piedras como los gentiles. En los } \\
\text { templos principales tenían gran cantidad de vírgenes muy } \\
\text { hermosas, conforme a las que hubo en Roma en el templo de } \\
\text { Vesta, y casi guardaban los mismo estatutos que ellas". }\end{array}$ & $\begin{array}{l}\text { "Habiendo grandes guerras entre los indios de este Reino, y } \\
\text { viviendo todos muy sin orden, haciendo grandes maldades } \\
\text { y delitos [...] permitió Dios darles otro mayor tirano que } \\
\text { los que antes les gobernaban, que con mayor crueldad y } \\
\text { tiranía los tratase y castigase. Este se llamó Mango Capa, } \\
\text { el cual fundó la ciudad del Cuzco, e hizo leyes a su gusto } \\
\text { y provecho, y no al de sus súbditos [...] Este Mango Capa } \\
\text { y sus descendientes se llamaron Ingas que quiere decir } \\
\text { reyes o grandes señores. Pudieron tanto, que señorearon y } \\
\text { conquistaron desde Pasto hasta Chile; y sus banderas vieron, } \\
\text { por la parte del sur, al río Maule, y por la parte del norte, al } \\
\text { río de Angasmayo, y estos ríos fueron término de su imperio, } \\
\text { que fue tan grande que hay de una parte a otra más de mil } \\
\text { y trescientas leguas, y para le conservar edificaron grandes } \\
\text { fortalezas y aposentos fuertes de piedra [...] Al sol tuvieron } \\
\text { por dios soberano, al cual hicieron grandes templos, y } \\
\text { engañados por el demonio, adoraban en árboles y en piedras, } \\
\text { como gentiles. En los templos prencipales tenían grand } \\
\text { [sic] cantidad de vírgenes muy hermosas, que llamaban } \\
\text { mamaconas, conforme a las que hubo en Roma en el templo } \\
\text { de Vesta, y casi guardaban los mesmos estatutos que ellas".28 }\end{array}$ \\
\hline
\end{tabular}

Comparando las dos versiones, notamos la flagrante manipulación que efectúa el licenciado al omitir en esta transcripción los atributos positivos que otorga Cieza de León a los Incas. Por ejemplo este último, al referirse a Manco Capac, señala que "estableció leyes a su usanza” (2005, p. 109), mientras que Matienzo (1730? [1567], f. 7r y 1967, p. 6) afirma que "hizo leyes a su gusto y provecho, y no al de sus súbditos". Por otra parte, el oidor omite un párrafo completo en el cual el cronista sostiene que los Incas "Hicieron grandes cosas, y tuvieron tan buena gobernación, que pocos en el mundo les hicieron ventaja [...] Pusieron en buenas costumbres a todos sus súbditos, y diéronles orden para que se vistiesen" (Cieza, 2005, p. 110). Tal omisión encubre un propósito evidente: dar una explicación razonada para negar la existencia de un "señorío natural" y propiciar una progresiva deslegitimación de las exigencias restitutivas de los Incas coloniales, apuntalados por clérigos y frailes de cuño lascasiano. Otro elemento interesante y poco explorado en la prosa justificativa del licenciado, es el énfasis mostrado en imputarle a Atahualpa la acción de una violenta usurpación, considerada esta una razón poderosa para privar del reino a los cusqueños:
Ha habido siete sucesores deste Mango Capa Inga, primer tirano, hasta Atagualipa [...] Este Atagualipa también fue tirano, porque siendo su hermano Guascar Inga, le mató y se quedo con el reino [...] Por estas razones parece que los ingas fueron tiranos, y no reyes naturales, pues aquél se dice tirano que, por fuerza o engaño, a traición toma y ocupa reino ageno, como estos Ingas lo hicieron, y aunque hobiera duda si eran reyes naturales, o no, se presume ser tiranos por las señales que luego diré (Matienzo, 1730? [1567], fol. 7r y 1967, pp. 6-7).

$\mathrm{Si}$ se consideran las apreciaciones formuladas por Duviols (1982, p. 17) respecto a los nuevos móviles que la cronística de 1550 imputaba para considerar tirano a este Inca, podemos observar que figura a la vez un fraticidio y un regicidio, lo que implica considerar a este como un "criminal". ${ }^{29}$ Estos móviles

28 Las cursivas son nuestras.

29 En el capítulo I existen dos declaraciones a este hecho; "Este atabalipa también fué tirano, porque siendo su hermano Guáscar Inga, le mató y se quedó con el reino" (1730? [1567], fol. 7r) y "como lo hizo Atagualipa, 
políticos aumentan la carga estereotípica con que fue reconocida la "monarquía" incaica en la Corte real y reafirman la convicción del uso estratégico que le dio el licenciado a este texto de Cieza, considerado como histórico.

Una vez explicada la fundación prehispánica del gobierno inca, el oidor se avoca de lleno a mostrar una serie de correspondencias entre este último y el mundo clásico. Este verdadero despliegue de semejanzas y analogías, ${ }^{30}$ que van acompañadas sistemáticamente por referencias autorales precisas a Platón, Aristóteles, Séneca y Santo Tomás, otorgan los fundamentos teóricos para naturalizar en los medios letrados castellanos la imposibilidad moral de restituir un señorío originado en la usurpación. En este sentido, Matienzo define una serie de "señales" a través de las cuales pueden ser "descubiertas" las prácticas políticas de los Incas, a saber: a) El provecho individual en desmedro del bien público; b) El empobrecimiento de sus súbditos y la imposición de un régimen laboral esclavizante (en el cual los indios no pueden "adquirir hacienda propia"); c) La crueldad manifiesta al asesinar, sacrificar y ultrajar a los naturales; d) Inscribir en sus vasallos el miedo; al ser reconocidos etnográficamente como "pusilánimes" y "temerosos"; e) Desnaturalizar a los indios, al expulsarlos a otras tierras sin posibilidad de retorno; ${ }^{31}$ f) Sospechar de todos sus súbditos, practicando un verdadero "nepotismo" prehispánico y g) Gobernar sin uso de leyes ni costumbres, mas haciendo uso de un voluntarismo irracional (Matienzo, 1730? [1567], fol. 10r-11v y 1967, pp. 7-10). Los siguientes capítulos (II y III) refuerzan, consecuentemente, el argumento que legitima la toma del poder por parte de los hispanos y cuyos argumentos han sido ya explorados (Góngora, 1951; Pereña et al., 1982). ${ }^{32} \mathrm{Si}$ se analizan las afirmaciones preceden-

que mató a Guascar Inga su hermano, y sucesor verdadero que era de Guayna Capa" (1730? [1567], fol. 11v y 1967, p. 10).

30 Por ejemplo, al comparar a Manco Capác, Atahualpa, Huáscar y Huayna Capác con Pisistrato (tirano de Atenas), Polícrates (tirano de la isla de Samos), Lucio Sila y Nerón (tiranos de Roma) y Dionisio el Viejo (tirano de los siracusanos).

31 Matienzo resignifica instrumentalmente la institución de los mitimaes, considerada la expresión máxima de la sujeción tiránica de los incas.

32 Estos argumentos serían: la donación pontificia, el tes, la intención jurídica del oidor es que los Incas fueron tiranos por ser "ilegítimos" en dos sentidos, quoad titulum (ilegitimidad de origen) y quoad administrationem (ilegitimidad de ejercicio), es decir, no llegaron al poder ni gobernaron de acuerdo a la ley (Pérez Fernández, 1988). La conclusión fundamental de todo su ejercicio retórico amparado en las fuentes clásicas (a través del uso de símiles), la cronística y la relación de los informantes cusqueños es sostener con ahínco que los Incas no fueron, bajo ningún punto de vista, "señores naturales" de sus dominios, promoviendo con ello la legitimidad de la usurpación española.

La función de los tres primeros capítulos de la obra -como hemos mencionado- es la demostración de la existencia de una tiranía como elemento probatorio de un gobernar ilegítimo y, consecuentemente, el indicio político para justificar los derechos de posesión de la Corona. ${ }^{33} \mathrm{~A}$ pesar de la autoridad de sus sentencias y el interés mostrado por derribar uno a uno los argumentos de licenciados y clérigos como Falcón y Las Casas, Matienzo manifiesta ciertas vacilaciones en su argumentación. En el capítulo I, nos dice: "Por tanto, aunque estos Ingas fueron reyes naturales del Perú, se podían llamar tiranos, pues concurrían en ellos las señales que arriba están dichas" (Matienzo, 1730? [1567], fol. 11v). ${ }^{34}$ Esta última cita muestra una contradicción que problematiza la posición que este jurista sostenía respecto a la ponderación de tal régimen político. Isacio Pérez (1988) aclararía esta situación señalando que el oidor entendió "naturales" en tanto "originarios", "oriundos del lugar" y no como "legítimos gobernantes". Sin embargo, el párrafo antes citado problematiza esta afirmación:

dominio universal del emperador, la circunstancia de que estos reinos estaban desiertos, la oposición de los indios a recibir la fe y los grandes pecados e infidelidad de estos.

33 El licenciado sostendrá que: "luego los españoles pudieron muy bien y justamente hacer guerra contra los ingas para que cesasen las dichas tiranías e sacrificios de indios que hacían al demonio, y ésta es causa bastante para que los indios pudiesen mudar nuevo príncipe" (Matienzo, 1730? [1567], fol. 12v y 1967, p. 11).

34 Las cursivas son nuestras. 
"los ingas fueron tiranos, y no reyes naturales, pues aquél se dice tirano que, por fuerza o engańo, a traición toma y ocupa reino ageno, como estos Ingas lo hicieron, y aunque hobiera duda si eran reyes naturales, o no, se presume ser tiranos por las señales que luego diré" (Matienzo, 1730? [1567], fol. 7r y 1967, p. 7). ${ }^{35}$

Y avanzado el capítulo XXXIX, referente a las huacas y enterramientos de indios, vuelve sobre lo mismo:

\section{[...] los Ingas no eran reyes naturales de estos} Reinos, sino tiranos que habían quitado y privado del señorío de sus tierras a los verdaderos y ligítimos reyes, que son los caciques principales de cada provincia; y aunque fueran reyes naturales, por las tiranías que usaban con sus súbditos se podían decir verdaderamente tiranos (Matienzo, [1567], fol. 99v y 1967, p. 130).

$\mathrm{Al}$ parecer, en estas citas el oidor hace mención a la condición de "natural" como equivalente al derecho regio y no al origen territorial, puesto que contradice su primera afirmación: primero los Incas "fueron reyes naturales" y luego "fueron tiranos y no reyes naturales". Esa reflexión sugiere, a lo menos, que el licenciado vivió un desafío político-jurídico al momento de imputar tan deleznable condición. Por ello, la construcción de la tiranía Inca implica la puesta en escena de un móvil justificativo y conveniente a la Corona, pero también un conjunto de buenas prácticas que en el siglo XVI no eran del todo incoherentes con el modelo del tirano (Mumford, 2011). Esta posición ambivalente queda clara al momento de describir las características del gobierno del mítico Manco Capac, al sostener que este "hizo leyes a su gusto y provecho, y no al de sus súbditos, aunque algunas fueron buenas y muy necesarias, y fueron hechas a buen fin" (Matienzo 1730?[1567], fol. 6v y 1967, p. 6). ${ }^{36}$

Los razonamientos precedentes -analizados in extenso por la historiografía del derecho indiano- se-

35 Las cursivas son nuestras.

36 Las cursivas son nuestras. ñalan a Juan de Matienzo como el burócrata que desprecia y condena la existencia de un orden fuera de toda ley natural. No obstante, la lectura de los capítulos posteriores -destinados al ordenamiento laboral y tributario de las comunidades andinas- parece esbozar un argumento complementario a estas primeras sentencias radicales y cimentadas sobre un ejercicio de especulación teórica en los campos del derecho natural. Atendiendo, como argumentamos más arriba, a la progresiva legitimidad que fue adquiriendo el conocimiento derivado de lo empírico, bajo el supuesto de que precisamente fueron burócratas y religiosos del siglo XVI los que vincularon este conocimiento con prácticas de dominio y administración (Brendecke, 2012), es posible constatar que los Incas son presentados como ejemplos de control, uniformidad, gobernabilidad, sujeción y policía. Esta constatación se presenta entretejida a las disposiciones y ordenanzas que sugiere el Gobierno del Perú a lo largo del texto, al momento de reglamentar la vida social y laboral de los indios.

\section{Compulsión laboral, organización tributaria y policía: los incas, ejemplo de sujeción}

En términos laborales, Matienzo es el responsable de un esfuerzo retórico por ordenar y reestructurar el trabajo indígena en el contexto de la urgente necesidad de aumentar las arcas fiscales, decrecientes desde 1550 (Bakewell, 1989). Uno de los grandes problemas que obsesionaron al oidor $-\mathrm{y}$ a juristas como Santillán y Ondegardo- era el problema del ocio y disipación de los indios, elemento que -según ellos- dificultaba la exigencia y ritmo laboral de acuerdo a las necesidades del mercado colonial. La argumentación de Matienzo, sobre la base de la teoría de la servidumbre natural de Aristóteles (Matienzo, 1967 [1567], fols. 15v-17v y 1967. pp. 17-18; Pagden, 1988), sostenía que por "naturaleza" los indios eran proclives al ocio, la holgazanería y la embriaguez, ${ }^{37}$ situación radicalmente opuesta a la

37 Las descripciones antropológicas sobre los indios figuran, a lo menos, en dos textos; en el Parecer cerca de la perpetuidad y buen gobierno de los indios del Peru y aviso de lo que deven hazer los encomenderos para salvarse, enviada al presidente del Consejo de Indias Juan Sarmiento en 1562 (Mo Romero, 1993, pp. 165-178), 
concepción de "bien común" y orden republicano propugnada por los letrados colonialistas (Góngora, 1951, p. 30). En este sentido, la práctica gubernamental incaica -observada por estos funcionariosimplicaba una representación de los cusqueños en dos sentidos: por una parte, el carácter pusilánime y temeroso del indio habría permitido el ejercicio tiránico sobre sus comunidades $y$, a la vez, habría generado una habituación servil, hecho evidenciado en la constatación etnográfica de la docilidad y mansedumbre de los naturales, carentes de voluntad y lanzados a la desidia y al desinterés por las formas de opresión a las que habrían sido sometidos. Matienzo se dedica a señalar que los Incas, hábiles gobernantes pero tiranos, habían producido una verdadera habituación al miedo en todos los indígenas sujetos por estos (Matienzo, 1730? [1567], fol. 6v-11v y 1967, p. 6). Al desaparecer dicha tiranía, los indios del común habrían quedado en calidad de siervos no pensantes y con una tendencia al ocio, la borrachera y la pusilanimidad. Esta afirmación conduce necesariamente a un segundo sentido: observar a los Incas como capaces de controlar esa naturaleza ociosa, es decir, continuar con un régimen provechoso en el disciplinamiento moral de los indios.

\section{Los Incas como ejemplo de compulsión laboral}

Si se analizan con detención los capítulos VI, X, XIV, XL, XLI (título V), así como el VI y XXXII de la segunda parte, dedicados en general a la reglamentación del trabajo indígena y al control de estos, podemos advertir un conjunto de fragmentos textuales que sugieren la hipótesis de que el estatuto político de los Incas -el hecho de ser tiranosfuncionó de forma no excluyente a una suerte de recuperación instrumental de los mecanismos de sujeción aplicados por estos. Las referencias directas a esta argumentación pueden ser clasificadas en dos ámbitos de gobernabilidad específicos: a) La disposición de los indios -yanaconas, mitayos, hatunrunas- para el trabajo reglamentado y como ob-

publicado en Pereña et al. (1982) y en el Gobierno del Perú, capítulo IV (Matienzo, 1730? [1567], fol. 11v-16v y 1967, pp. 16-19) jeto de disciplinamiento, ${ }^{38}$ y b) El mantenimiento de algunas instituciones incaicas como el tocuirico y los chasquis, además del hecho de que los Incas uniformaron la llamada "lengua general" (experiencia previa a la castellanización del centro-sur andino, sostenida por el propio Matienzo) (Castro e Hidalgo, 2016).

En el capítulo VI, "De la ocupación que deben tener los caciques y principales, y de sus asientos y orden", Matienzo (1730?[1567], fol. 18v-20r y 1967, pp. 20-22) específica sobre la necesidad de imponer un proceso de castellanización (leer y escribir) paralelo al fenómeno reduccional que permita la instrucción de la doctrina cristiana. Una referencia previa a la uniformidad lingüística del Tawantinsuyu era justamente la aplicada por los dirigentes cusqueños. Al determinar el imperativo a los caciques de hablar y escribir en castellano, sostenía que debían aprenderla "como hicieron con la lengua general que aprendieron todos por mandado del Inga" (Matienzo, 1730?[1567], fol. 20r y 1967, p. 21). Sin considerar este párrafo como una apología al orden prehispánico, es sugerente percibir una referencia explícita al hecho de "como hicieron los Incas” en tanto experiencia previa de uniformidad y hegemonía lingüística, mecanismo que claramente allanó el camino hacia un control imperial de las poblaciones sujetas.

En relación a la reglamentación del trabajo indígena, el licenciado pone énfasis tanto en la tributación y función laboral de estos -al clasificar en un estricto orden a yanaconas, hatunrunas y tindarunas en su correspondiente oficio- como en la polémica controversia de cargarlos para el transporte de mercaderías (Matienzo 1730?[1567], fol. 29r-32r y 1967, pp. 36-37). El problema de cargar abusivamente a los indios había sido denunciado por el arzobispo de Popayán Juan del Valle en 1548, quien había enviado al clérigo Luis Sánchez a la metrópoli, dándole una instrucción para presentarse ante el Consejo de Indias y denunciar este y otros abusos. Del mismo modo, el arzobispo denunciaba en 1558 la misma situación tiránica contra los naturales (Pérez Fernández, 1988, p. 298). Esta crítica será reproducida

38 Para una explicación pormenorizada de esta clasificación, ver Góngora (1951). 
años más tarde por diversos curas y licenciados, entre los cuales figuran Francisco Morales (1561), Bartolomé de la Vega (1563) y Francisco Falcón (1567). Frente a ello, Matienzo replicaba que:

El daño que a los indios viene de cargarse es solamente en un caso: cuando la carga es inmoderada, o cuando no se la pagan. De otra manera, antes les viene provecho de ello, porque ellos -como dixe arriba- desde que nacieron son hechos a cargarse; y en el tiempo del Inga nenguno entraba ante él que no fuese cargado, y él puso esta orden en los tambos, para que los mitayos allí puestos llevasen las cargas de la gente de guerra e del mesmo Inga e de sus capitanes, y no les pagaban por ello cosa alguna. Ellos no se desprecian de traer cargas [...] y si les pesa por llevar cargas, no es por la pesadumbre que les da, ni porque se afrentan de ello, sino porque son amigos de ociosidad y aún no están inclinados a tener cosa propria [sic] (Matienzo, 1730?[1567], fol. 30r-30v y 1967, pp. 36-37). ${ }^{39}$

En esta cita observamos dos argumentaciones complementarias: la naturaleza de los indios (ociosa y servil) y la referencia directa al Inca, en términos de sujeción y reglamentación normativa, elemento que debe ser mantenido en el orden "republicano" que ha planificado. La alusión a las disposiciones del Inca implican una legitimidad a la regulación colonial que permite "cargar" a los indios, naturalizando una función servil de larga data en los Andes, sostenida axiológicamente por las autoridades prehispánicas dada la natural inclinación de aquellos. $\mathrm{Al}$ igual que muchos clérigos -sobre todo los artífices coloniales de la "utopía incaica" como el Jesuita Anónimo, Blas Valera y Luis López y, más tarde, el Inca Garcilaso-, el mercedario Martín de Murúa argüía que "todos confiesan que si el día de oy fueran rejidos conforme lo fueron de los yngas, travajaran mas los indios y se bieran maiores efectos de su sudor, y se fueran augmentando en ynfinito número" (Murúa, 1964 [1616], p. 36). La eficiencia de esta compulsión laboral observada con asombro es establecida por el oidor al momento de reglamentar el

39 Las cursivas son nuestras. trabajo minero de los naturales; en el capítulo XL, "De los asientos de minas de Potosí y de Porco; si conviene que los indios se echen a las minas, y cómo se han de conservar los asientos", utiliza de forma conveniente la referencia al Inca:

En el tiempo que los Ingas mandaron este gran Reino del Perú, sacaban en algunas partes de esta provincia de los Charcas gran cantidad de plata, teniendo muchos indios para ello, especialmente en el cerro de Porco, que ha sido la cosa más rica que se ha visto. Cuando entraron los espańoles, hallaron las vetas descubiertas y labradas, y han sacado de ellas gran cantidad [...] Toda esta provincia está llena de metales, y por no sacarlos con indios, y ser fría para negros, está perdida esta riqueza [...] conviene por la conservación del asiento y del Reino, que los indios anden en la labor de las minas, y para esto se reparta entre todos los repartimientos de indios, conforme a los que cada repartimiento o provincia tiene, repartiéndolos los caciques como lo hacian en tiempo del Inga.." (1730? [1567], fol. 101r y 1967, pp. 132-134). ${ }^{40}$

Sin duda, el control fiscal sobre la explotación argentinífera de Porco y la disposición de indios para ello, organizan argumentalmente los últimos capítulos de la primera parte. Para Matienzo, la recuperación de un sistema eficiente de tributación indígena -en que los negros quedan excluidos- constituye una prioridad en el ámbito de las decisiones gubernamentales, al constatar la riqueza del Alto Perú. La mita minera y su reorganización implicaba -hacia 1567- el mantener las "leyes del Inca" a través de un sistema rotativo de prestación de la fuerza laboral nativa (sugerido visionariamente en 1562 por Polo Ondegardo) (Zagalski, 2014). Esta prestación regulada será esencial "para la conservación del asiento y del Reino" e implicaba que los caciques repartieran a los indios "como hacían en tiempo del Inga". Cuando reglamenta -a su vez- la función específica de los llamados "mitayos de tambos", encargados de llevar cargas de un Tambo a otro, explica la continuidad colonial que le dio Vaca de Castro a esta función,

40 Las cursivas son nuestras. 
disponiendo de ordenanzas que "hizo conforme a las del Inga, que hasta hoy se guardan" (Matienzo, 1730? [1567], fol. 29r y 1967, p. 35).

Las argumentaciones precedentes sostienen una estructuración y reformulación colonial de la mita minera y una recuperación de un estable sistema tributario que permitía un sistema de prestación equilibrado y rotativo (Góngora, 1951). Es necesario recordar que bajo el orden republicano dispuesto por el oidor, los naturales, clasificados funcionalmente bajo el precepto aristotélico de la condición servil, sostienen y articulan el trabajo del que dependen las demás clases y castas coloniales, ya que "los españoles no trabajan" (Matienzo, 1730? [1567], fol. 105v y 1967, pp. 136-37). Paralelamente a su esfuerzo -muchas veces encubierto- de utilizar las políticas incaicas como referencia para el orden colonial que él proyecta, es posible observar algunas afirmaciones que sustentan la idea de un orden incaico disciplinador en relación a la conducta de sus gobernados. En el capítulo XLI del Título V, referente a disposiciones tocante a minas, socavones y despoblados en Porco y Potosí, dedica un acápite a establecer un cuerpo de normas para los yanaconas, ${ }^{41}$ una clase de indios que no estando bajo la estricta tutela de los españoles han disipado su conducta. Estos yanaconas, perdidos y sin amos, "andan robando [...] e haciendo otros grandes delitos, y lo que peor es, que corrompen las buenas costumbres de otros indios que están trabaxando y les enseñan a ser ladrones" (1730? [1567], fol. 113v y 1967, p. 145). El inconveniente detectado por el licenciado radica en el hecho de que estos dan un mal ejemplo al resto de los naturales, lo cual

41 En el capítulo VIII de la primera parte, Matienzo explica que los yanaconas son "indios que ellos, o sus padres, salieron del repartimiento o provincia donde eran naturales, y han vivido con españoles sirviéndoles en sus casas, o en chácaras y heredades, o en minas" (1730? [1567], fol. 22r y 1967, p. 25). Esta clase de indios -siguiendo su razonamiento-, al vivir con españoles, se han cristianizado y aprendido un conjunto de oficios técnicos, han aprendido a adquirir "hacienda propia" y poseen más "honra" que los propios caciques pero, al mismo tiempo, han aprendido los vicios y artimañas de sus dominadores. Su rol fue considerado axial en la maquinaria económica colonial.
[...] podría redundar en que todos hurtasen, que sería tan gran mal que no se pudiese vivir en este Reino, y se violase una tan buena costumbre que tienen todos en general, y que les quedó del tiempo de los Ingas, que es no se atrever a hurtar plata ni oro, antes yo he visto algunos que si ven alguna plata en el suelo se desmayan y no se quitan de allí hasta que venga español, o se lo van a decir a cualquier español para que lo vengan a alzar, que no osan de miedo tocar a ella, y ansi, en tiempos antiguos, no eran menester puertas, ni arcas o caxas en que se guardase la plata, antes se dexaba en el suelo, y no había quién la hurtase. Agora hay munchos yanaconas que han vivido como españoles, que agora andan holgazanes, que hurtan hasta las lámparas de las iglesias..." (1730? [1567], fol. 113v y 1967, p. 145). ${ }^{42}$

Este conjunto de afirmaciones puede cotejarse con una declaración formulada en el capítulo VIII, referido a esta clase de indios, en que implícitamente se deja entrever el orden policial establecido por los cusqueños. Al sostener el peligro que conllevaría el permitir el retorno de los yanaconas a sus repartimientos, puesto que enseñarían a los hatunrunas sujetos a sus caciques "malas costumbres", hace una implícita alusión a un orden moral estricto. ${ }^{43}$ Para Matienzo, los yanaconas han aprendido a mentir y manipular el sistema judicial hispano, "cosa que antes que viniesen españoles no sabían hacer, antes confesaban de plano aunque luego les hubiesen de matar" (Matienzo, 1730? [1567], fol. 25v y 1967, p. 30). Para el oidor esta costumbre, que sustenta una moralidad específica, fue viciada por la presencia espańola y, consecuentemente, traspasada a los yanaconas. Sin decirlo, el licenciado atribuye a los Incas el articular un férreo control de las "buenas costumbres", elemento de alta conveniencia en las prácticas de sujeción y "policía”. Siguiendo

42 Las cursivas son nuestras.

43 Para el licenciado vallisoletano, el orden y "policía" colonial radicaba en separar a las comunidades de indios (hatunrunas) sujetas a sus caciques (repartimientos) de los indios castellanizados yanaconas, evitando la proliferación en aquellos de vicios y mecanismos contrahegemónicos y considerados causa de una eventual "pérdida de la tierra". 
esta argumentación, podemos apreciar una estrecha relación entre el Inca y el disciplinamiento morallaboral de sus gobernados cuando describe, en la segunda parte del Gobierno del Perú, las características de los indios de la audiencia de Quito. Su descripción los menciona como "más domésticos y bien inclinados que los del Perú", "grandes labradores" ya que "han vivido con los mesmos ritos que los Ingas [...] porque fueron conquistados por ellos, $y$ ellos les dieron la orden de vivir que agora tienen, porque antes no eran tan industriosos" (Matienzo, 1730? [1567], fol. $213 \mathrm{v}-214 \mathrm{r}$ y 1967 , p. 247). ${ }^{44}$

La importancia de esta cita radica en el hecho de entender al Estado inca como un aparato normalizador de la conducta social de las comunidades andinas, inscribiendo en los nuevos vasallos un orden político y laboral sin precedente alguno en los Andes prehispánicos. Los párrafos citados, que utilizan como referencia directa e indirecta la política incaica de sujeción, dan luces de un argumento que nos ha parecido plausible: el hecho de considerar que para Juan de Matienzo el orden tiránico era coherente con un tipo de disciplinamiento laboral y moral de los sujetos gobernados, que fue exitoso para el mantenimiento de la fuerza laboral-tributaria, necesaria a las exigencias de un imperio ávido de la mano de obra de sus súbditos. La constatación empírica de la naturaleza inherente de los indios permitió legitimar las prácticas "tiránicas" de los Incas, al momento de disciplinar el ocio y acceder a la fuerza de trabajo por vía de imposición forzosa. El licenciado, incluso cuando declara el nefasto e ilegal ejercicio de abusar del trabajo de los naturales, no deja de esbozar cierto asombro en términos de grandeza y efectividad:

Hacíanles tambien hacer acequias y calzadas mas insines y mayores que las que hicieron los romanos, y hacer en sierras y cuestas muy altas y llenas de piedras y peñas, andenes de piedra, para que pudiesen sembrar en ellos, subiendo la tierra de los Llanos para poder sembrar mejor y más fértil: cosa increible a los que no lo han visto. Todo para nos le dexar un punto ociosos" (Matienzo, 1730? [1567], fol. 10r y 1967, p. 8).

44 Las cursivas son nuestras.
A pesar de que este párrafo se encuentra al interior del capítulo I, destinado a probar una cruel tiranía, parece sugerir una descripción positiva tanto de los logros materiales alcanzados, incluso superiores a los romanos, como de la capacidad de los Incas para erradicar el ocio. En el siglo XVI español, la peligrosidad de un sujeto ocioso no radicaba tanto en ser un peligro en términos de su eventual situación de delincuencia, sino "porque este representaba un estado de improductividad dentro de una estructura económica dependiente de la fuerza laboral de sus integrantes" (Araya, 1999). En la documentación colonial como archivos judiciales, tratados jurídicos, cartas e informes, la presencia de esta calidad -en términos laborales- constituía una preocupación fiscal de gran envergadura; la culpabilidad de un ocioso se sustentaba en su relación con el trabajo, además de las conductas que traía aparejadas. La relación entre ocio y trabajo "fue considerada de suma importancia, constituyendo un objeto de vigilancia que implicaba la movilización de recursos para su corrección" (Araya, 1999). Por ello, la particular tiranía que reconocía Matienzo en los Incas era eficiente y moralizadora al "corregir" eficazmente una "mala inclinación".

\section{La recuperación de la "pulicía" incaica; el tocuirico y los chasquis}

A su llegada al Perú, los conquistadores se percataron de la existencia de dos instituciones incaicas consideradas vitales en la labor gubernamental desplegada por estos al momento de controlar y gobernar las provincias apartadas del Cusco. Tanto el tocuirico o trocricoc como los chasquis o cachac expresaban las lógicas de un Estado prehispánico en expansión que necesitaba de administradores o funcionarios hábiles para facilitar el control político y el monopolio de los factores productivos enajenados (Rostworowski, 1988). Su presencia en los Andes coloniales figura en algunos pasajes del Gobierno del Perú como una práctica gubernamental necesaria y que debía ser recuperada y sobrevivir en la Colonia, según Matienzo (Duviols, 1977).

El cargo de tocuirico (tocricoc) posee diversas referencias documentales. Felipe Guaman Poma los describe como "Tocricoc, juez, Michoc, estos ingas fueron 
de la parcialidad de Tambo Inga o auquicona [...] fueron corregidores de provincias y jueces que va a tomar cargo y residencia”. Asimismo, determinaba su probidad funcionaria; "Y estos dichos corregidores hacían buena justicia y no robaban, ni tenía tratos y contratos [...] ni nadie se quejaba de ellos (Guaman Poma, 1980 [1615], p. 251). Una información elaborada en el Cusco en 1582, por orden del Rey y encargo del virrey Martín Enríquez acerca de las costumbres que tenían los Incas" (Levillier, 1925), ${ }^{45}$ los señala como "persona principal y este le ponia el ynga por el tienpo que el quería y quel mando y jurisdiscion que tenia era ver como cumplían los caciques lo que cada uno estava obligado a hazer en su lugar e que el oficio destos era ser sobreestantes de lo que el ynga mandava" (Levillier, 1925). Con todo, eran funcionarios que observaban y vigilaban el cumplimiento de las leyes impuestas por el Inca y el desempeño de los curacas en esta imposición. La función colonial que Matienzo le otorga a este antiguo cargo, similar al corregidor de indios, consideraba que en cada repartimiento debía haber

[...] un tocuirico (que quiere decir: todo lo ve), que ha de traer vara. Este ha de ser indio ladino, estrangero, y no de aquel repartimiento sino de otro bien lexos, para que no tenga deudos con los de aquel repartimiento, y no ha de estar muncho tiempo, por que no se haga con los caciques, y ellos le sobornen para que calle sus tiranías, como ordinariamente hasta aquí han hecho a españoles. $\mathrm{Ha}$ de estar un año, o dos a lo más largo, y hále de tomar residencia otro que viniese. Lo que ha de hacer es tener memoria, por escrito si supiere leer, y no lo sabiendo, por quipo, de cuantos indios hay en el repartimiento, y de la edad de cada uno, por casas [...] Poner los que son cristianos, y los que no lo son. Ha de dar esta cuenta cada ańo al Corregidor espańol del repartimiento, e no lo habiendo, a el de la ciudad, para que se entienda cuántos se han muerto, cuántos nacido, y cuántos llegado a la edad suficiente para poder pagar

45 Informe elaborado a partir de las declaraciones de García de Melo, Damián de la Bandera, Cristóbal de Molina, Alonso de Mesa, Bartolomé de Porras y algunos indios. tasa (Matienzo 1730? [1567], fol. 39v-40r y

1967, p. 52).

Estas funciones específicas son consignadas como un cuerpo de leyes que incluyen, además, la función de controlar la limpieza e higiene de las calles (Matienzo, 1967 [1567], p. 56). Para Moreno Cebrián (1977), esta autoridad pondría freno a la ambición de los curacas respecto al orden tributario y fue reinstalada por el arzobispo Jerónimo de Loaysa por consejo de José de Acosta y el propio Matienzo (Muro Romero, 1976). El sentido gubernamental que le otorga el oidor de Charcas sigue de cerca el sentido inca, pero ańadiendo algunos aspectos propios de la noción de policía moderna, es decir, debía el tocuirico organizarse alrededor de un campo de visibilidad y vigilancia, concentrando en su persona los poderes de control, de inquisición y represión. Entre otras cosas, debía velar por la "pureza de costumbres, la limpieza de las casas y las calles del pueblo, la estricta observancia de la moral sexual, la prohibición de comer todos juntos en la plaza, en vez de hacerlo cada uno en su casa como hombres de razón, el control de la asistencia a la instrucción religiosa, etc." (Duviols, 1977; Coello de la Rosa, 2000). La función de este cargo fiscal -en su sentido básico- fue planteada como necesaria al orden colonial, dada la naturaleza de las comunidades indígenas y, en específico, de sus dirigentes, los curacas. Con ello, Matienzo pretendía limitar su poder y disponer de un control transparente y directo sobre los indios del común, aspecto casi imposible sin la intermediación de aquellos.

Por su parte, la institución de los chasquis posee también referencias precisas en la cronística colonial de interés indígena. Pedro Cieza de León -referencia obligada de Matienzo- en su Crónica del Perú (segunda parte), ${ }^{46}$ argumenta: "En fin, por esto y por en todo acertar a gobernar las provincias, los Ingas inventaron las postas, que fue lo mejor que se pudo pensar ni imaginar" (Cieza de León, 2005 [1553], p. 345). La efectividad de los chasquis es presentada por Juan de Betanzos al sostener que "en ocho días sabía el Ynga en la ciudad del Cusco lo que se hacia en el Quito y sus provincias que son mas de trecientas leguas las que hay del Quito al Cusco y asimismo

46 Nominada el "Señorío de los incas". 
le llevaban el pescado fresco en tres días desde la costa al Cusco, que son ciento veinte leguas" (Betanzos, 1987 [1551], p. 113). Por su parte, el Inca Garcilaso de la Vega los describe como "correos que había puestos por los caminos, para llevar con brevedad los mandatos del Rey y traer las nuevas y los avisos que por sus reinos y provincias, lejos o cerca, hubiese de importancia" (1976 [1609], T. II, p. 22) y luego es uno de los pocos en determinar la naturaleza de su función específica. "Llamáronlos chasqui, que quiere decir trocar, o dar y tomar, que es lo mismo, porque trocaban $[. .$.$] los recados que llevaban [\ldots]$ El recado o mensaje que los chasquis llevaban era de palabra [...] las palabras eran pocas y muy concertadas y corrientes (1976 [1609], pp. 22-23).

La particularidad de esta forma de control de la información generó en la cronística una admiración digna de ser comparada con la red vial romana, $y$ permitió seguir sustentando la idea utópica de un imperio perfecto en su administración. ${ }^{47}$ Pero esta cronística solo describía en términos apologéticos, sin mucha incidencia en las decisiones gubernamentales. Para la burocracia letrada $-y$ considerando la prosa política de Juan de Matienzo-, la recuperación de esta institución incaica debía plantearse bajo un preciso esquema normativo sobre la base de un conocimiento devenido de lo empírico. La recomendación de Matienzo adquiere un tono de disposición legal, en el capítulo XXXII [segunda parte], "De los correos o chasquis que en este reino conviene que haya" explica, en primer lugar, que

\section{Habíaseme olvidado de decir una general cos-} tumbre que tenían los Ingas, y era que ponían por los caminos chasquis (que quiere decir "correo de a pie"), que corría cada uno media legua, y tenían sus chozas en el camino, que hoy día duran, aunque no tan bien aderezadas como antes. Con estos chasquis sabía el Inga, estando en el Cuzco, lo que pasaba a trescientas leguas en siete $u$ ocho

47 En efecto, la construcción discursiva que magnifica la grandeza de la organización sociopolítica de los incas, comenzaría con la cronística a partir de 1550 . Son justamente los casos de Pedro Cieza de León (1553) y Juan de Betanzos (1551), los más reconocidos por dedicar especial atención al carácter civilizado de esta sociedad. días, lo cual también se usó en tiempo de las alteraciones de Gonzálo Pizarro y de Francisco Hernández Girón, que ansí de su parte, como de Su Magestad, había puestos chasquis que en breve tiempo avisaban de lo que pasaba en el otro campo (Matienzo, 1730? [1567], fols. 335r-336r y 1967, p. 356). ${ }^{48}$

La necesidad de su reinstalación colonial está fuertemente vinculada a las exigencias estratégicas de la administración colonial. Esta "general costumbre" no solo permitió a las autoridades peninsulares estar informadas de lo acontecido, previniendo rebeliones y levantamientos antifiscales, sino poder poner en práctica los dispositivos de sujeción a partir del conocimiento e información de los territorios dominados, sobre todo los más lejanos. Matienzo advierte que

[...] para siguridad de la tierra, se había de mandar que hobiese chasquis desde Lima al Cuzco, y desde el Cuzco a esta ciudad [se refiere a La Plata], para que en breve se sopiese lo que pasaba trescientas leguas de aquí, porque podría ser que habiendo algún alboroto tomasen los caminos para que no pasasen españoles, y podrían avisar por chasquis que corriesen fuera del camino [...] y que los que tan lexos estamos fuésemos en breve avisados de lo que Vuestra Magestad manda, que desde que se invían los despachos de Lima a esta Corte, se pasa la coyuntura de poder responder a ellos a la otra flota que viene (Matienzo, 1730? [1567], fols. 335r-335v y 1967, p. 356).

Consecuente con esta descripción funcional y explicada la necesidad de mantener esta práctica gubernamental, describe el cuerpo normativo que debiese ser atendido por el Rey y su Consejo: "Que pareciendo al Gobernador ser necesario, haga poner indios chasquis en los caminos de Lima y de los Charcas, para dar o recebir avisos, a los cuales se les pague del común de los indios, o de donde mexor le pareciere" (Matienzo, 1967 [1567], p. 356). Parece curioso, en este sentido, que el capítulo dedicado

48 Las cursivas son nuestras. 
al mantenimiento colonial de esta práctica (cap. XXXII, segunda parte) sea el último con el cual finaliza el tratado, es decir, el Gobierno del Perú culmina con una recomendación de aplicación imperativa: el mantenimiento de una institución incaica.

\section{Conclusiones}

Las argumentaciones precedentes imponen una reflexión analítica peregrinamente sustentada por J. Mumford $(2011,2012)$ para el corpus toledano, es decir, la imputación de los Incas como tiranos implica dos aspectos necesariamente complementarios: por una parte, una justificación política y axiológica frente a los cuestionamientos lascasianos sobre el modus operandi de la conquista del Perú y la usurpación de un señorío "naturalmente" constituido. Por otra, la realidad colonial hacia 1570 evidenciaba -sobre la base de una indagación etnográfica, otorgando un valor de primera mano a la empiria- la necesidad de "recuperar" algunos de los dispositivos de control económico operados por el Inca, frente a la imposibilidad de mantener el régimen tributario en el contexto colonial del siglo XVI. En otros términos, el conocimiento etnográfico permitió la producción de un saber instrumental al ejercicio de gobernabilidad virreinal y reorientó, en la praxis, una serie de medidas elaboradas en los círculos cortesanos de poder en la metrópoli. En este sentido, la reducción toledana -siguiendo a Mumford (2014) - pudo ser entendida también como la restauración de un orden prehispánico perdido; la gobernabilidad hispana comprometía un esfuerzo de recuperar una imagen española del Imperio incaico. Tempranamente, entre 1540 y 1560, funcionarios de la talla de Polo Ondegardo y Vaca de Castro habían declarado que "los incas habían impuesto un orden social perfectamente encuadrado en las necesidades del pueblo andino" (Saito et al., 2014, p. 137) y, más tarde, religiosos como el Jesuita Anónimo (1590) y el mercedario Martín de Murúa (1616) sostenían la capacidad de los Incas de sujetar a poblaciones enteras, argumentando sobre el talento de estos para conocer a sus gobernados en su naturaleza más profunda. Esta capacidad, reconocida en los autores mencionados, fue deducida a través de la observación in situ para sostener que una estructura de poder tan eficaz fue producto de una combinación de autoridad y conocimiento estatal de la alteridad (Saito et al., 2014, p.130). La contradicción de Francisco de Toledo y de sus predecesores -incluido Juan de Matienzofue imputar a los Incas la condición de tiranos y, al mismo tiempo, considerar que este régimen fue necesario dada la particular naturaleza de las sociedades andinas, inmutables al devenir histórico: el hecho de ser ociosos, flojos y pusilánimes. Por ello, el modelo de la tiranía no era del todo perjudicial para sujetos claramente inferiores y poco laboriosos, ya que tal régimen -en sentido clásico- "significaba el reducir a los súbditos a unidades atomizadas e intercambiables, que carecían de propiedad e iniciativa individual" (Saito et al., 2014). Si, por un lado la tiranía incaica había procurado una falta de iniciativa individual y enajenación de la propiedad individual, por el otro tenía la capacidad de no permitir el ocio y de cautelar la vida en policía de sus subordinados, evitando abominaciones, borracheras y desenfrenos.

Es importante señalar que Juan de Matienzo había expresado esta contradicción ańos antes de la intervención toledana y presumiblemente haya incidido en la percepción que el virrey Toledo tuvo posteriormente sobre el régimen inca (elemento escasamente analizado entre los historiadores dedicados a Toledo). A través del análisis a la primera parte, hemos podido constatar la presencia de dos relatos que se articulan a conveniencia y que reproducen la contradicción de la burocracia virreinal frente a un sistema de poder altamente eficiente en la exigencia laboral y moral de sus súbditos. Con todo, ¿cómo pueden ser convergentes estas dos posturas discursivas que describen a los Incas como tiranos y ejemplos de sujeción y gobernabilidad? ¿De qué manera fue posible tomar como referencia de autoridad un sistema político signado de tiránico y repudiado en la tradición clásica y escolástica? Es díficil saber en profundidad lo que el oidor intentaba probar al momento de imputar la tiranía y, al unísono, promover una restitución de ciertas instituciones incaicas. Parece plausible creer -como lo afirma Mumford (2012) - que la observación del gobierno incaico, que comprometía además una exégesis de la cronística peruana, permitió sostener que a pesar de que el modelo de tiranía calzaba con sus prácticas políticas, 
este fue necesario para gobernar a la población andina. La condición ontológica de los indios, asunto de primer orden en el Gobierno del Perú, legitima implícitamente la sujeción tiránica al momento de poner en evidencia que esta política fomentó el control social y la vigilancia, logrando erradicar el ocio entre los naturales.

Lo que hemos venido explicando nos conduce hacia dos direcciones analíticas con que puede ser observado el Gobierno del Perú: a) La razón gubernamental, orientada a la racionalización progresiva de los recursos productivos y su control. Este conjunto de "tecnologías de gobierno" (Foucault, 2006; Castro Gómez, 2010), cuya problematización contiene una racionalidad específica, determinará que el acto de gobernar signifique administrar adecuadamente las riquezas, el territorio y, sobre todo, las poblaciones. El Gobierno del Perú, a lo largo de sus ochenta y cuatro capítulos, se hace cargo de las complejas relaciones entre las riquezas, la población y el territorio a través de la utilización de un conocimiento experto, el de la economía política. Este tipo de conocimiento caracteriza, sin duda, la emergencia colonial de la racionalidad moderna en el control eficiente de la fuerza laboral de los vasallos. Por otra parte, y como segunda dirección analítica, b) Este tratado político-jurídico se vale de un fuerte sentido del pragmatismo, derivado de la empiria y de la consecuente autoridad etnográfica de sus descripciones, lo que redunda en una flagrante ambivalencia sobre la "tiranía incaica". A la vez, sustenta la relación progresiva entre el conocimiento empírico con modalidades específicas de intervención y administración, propia de lógicas modernas de gobernabilidad.

Las disposiciones laborales y tributarias para los indígenas atravesaban, hacia 1567, por una controversia casi siempre insuperable: el contexto de un cambio gradual del sistema de encomiendas, y por extensión de su perpetuidad, hacia el control estatal de la mano de obra y capitación individual, procesos que no podían desarrollarse sin la compulsión laboral comunitaria articulada por curacas (Stern, 1986, p. 61). Las opiniones jurídicas y políticas no convergían en un acuerdo de cómo debía realizarse este progresivo desplazamiento sociotributario, y el corpus textual de clérigos, licenciados y frailes recu- saba cualquier intento de compeler forzosamente a los indios fuera de su voluntad (Lohmann, 1966; Góngora, 1951). La sociedad colonial española dependía de los indios en sus necesidades más básicas e inscribía en estos la capacidad de desarrollar exclusivamente oficios mecánicos (Stern, 1986, p. 62). En este sentido, la necesidad de perpetuar un sistema precolombino que era efectivo en la compulsión laboral a nivel comunitario, parecía una solución pragmática frente a un cúmulo de factores inquietantes para la burocracia virreinal, en el decenio 1560-70. Siguiendo las reflexiones de Steve Stern, no cabe duda de que figuras como Domingo de Santo Tomás, Polo Ondegardo, Hernando de Santillán, Francisco Falcón, Juan de Matienzo, entre otros, se convirtieron en observadores experimentados y astutos, exhortando "a la Corona a basar su explotación de las economías autóctonas en el respeto de las relaciones y las prerrogativas tradicionales de la sociedad andina”. En la medida de lo posible, y compatibilizando con los intereses de la Corona, la "política real debía extraer los productos y la mano de obra excedentes de las economías autóctonas existentes, en lugar de reorganizarlas y controlarlas directamente" (Stern, 1986, p. 83). Por ello, la labor etnográfica emprendida largamente por Matienzo recurre a una objetivación necesaria para la exacción fiscal, argumentando y sugiriendo, a la vez, continuar con el régimen incaico tan provechoso en el disciplinamiento de la moral de los indígenas, a pesar de "demostrar" las prácticas tiránicas de aquellos.

\section{Agradecimientos}

Agradecemos a la Dra. Soledad González que a través del FONDECYT 11160141 nos facilitó la copia del manuscrito original existente en la New York Public Library. Agradecemos también los comentarios de los evaluadores que permitieron mejorar la primera versión de este artículo.

El presente artículo se inscribe en el marco del Proyecto FONDECYT de Iniciación 11180045 (CONICYT), Letrados, etnografía y proyecto de sujeción colonial. Los indios y los incas en la pluma de la burocracia virreinal, Perú 1557-1571, del cual el primer autor es investigador responsable. 


\section{Referencias citadas}

Alfonso el sabio (1807). Las siete partidas. Tomo II. Madrid: Imprenta Real.

Aranda, F. (Coord.) (2005). Letrados, juristas y burócratas en la España moderna. Cuenca: Ediciones de la Universidad de Castilla-La Mancha.

Araya. A. (1999). Ociosos, Vagabundos y Malentretenidos en Chile colonial. Santiago: Lom, Dibam, Centro de Estudios Barros Arana.

Aristóteles (1932). La Politica. París: Casa Editorial Garnier Hermanos.

Bakewell, P. (1989). La maduración del gobierno del Perú en la década de 1560. Historia Mexicana, XXXIX(153), 41-70.

Betanzos, J. (1987 [1551]). Suma y narración de los incas. Madrid: Ediciones Atlas.

Brading, D. (2015 [1991]). Orbe Indiano. De la monarquia católica a la república criolla, 1492-1867. México: Fondo de Cultura Económica.

Brendecke, A. (2012). Imperio e información. Funciones del saber en el dominio colonial español. Madrid - Frankfurt: Iberoamericana - Vervuert.

Castañeda, F. (2002). El indio: entre el bárbaro y el cristiano en Las Casas, Sepúlveda y Acosta. México: Alfaomega.

Castro-Gómez, S. (2010). Historia de la gubernamentalidad. Razón de Estado, liberalismo y neoliberalismo en Michel Foucault. Bogotá: Siglo del Hombre Ediciones.

Castro-Klaren, S. (2001). Historiography on the Ground. The Toledo circle and Guamán Poma. En Rodríguez, I. (Ed.). The Latin American Subaltern Studies Reader (pp. 143-171). Durham and London: Duke University Press.

Castro, N. e Hidalgo, J. (2016). Las políticas de la lengua imperial y su recepción en la audiencia de Charcas (siglos XVI-XVIII). Diálogo Andino, 50, 181-206.

Cieza de León, P. (2005 [1553]). Crónica del Perú, El señorio de los Incas. Caracas: Biblioteca Ayacucho.

Clifford, J. (2001 [1998]). Dilemas de la cultura. Antropolo- gia, literatura y arte en la perspectiva posmoderna. Barcelona: Gedisa.

Coello de la Rosa, A. (2000). El barro de Cristo. Entre la Corona y el evangelio en el Perú virreinal (1568-1580). Barcelona: Universitat Autónoma de Barcelona.

Colajanni, A. (2004). El virrey Francisco de Toledo como el primer "antropólogo" aplicado de la Edad Moderna. En Laurencich, L. y Numhauser, P. (Eds.). El Silencio Protagonista. El primer siglo jesuita en el virreinato del Perú 1567-1667 (pp. 51-94). Quito: Abda Yala.

Cummins, T. (2002). Forms of Andean Colonial Towns, Free Will, and Marriage. In C. Lyons and J. Papadopoulos (Eds.). The archaeology of colonialism (pp.199-240). Los Angeles: Getty Publications.

Curatola, M. y De la Puente, J. (Eds.) (2013). El quipu colonial. Estudios y materiales. Lima: Ed. PUCP.

Duviols, P. (1977 [1971]). La destrucción de las religiones andinas (durante la Conquista y la Colonia). México: Universidad Nacional Autónoma de México.

Duviols, P. (1982). Revisionnisme historique et droit colonial au 16ème siécle: le thème de la tyrannie des incas. En Indianité, ethnocide, indigénisme en Amérique latine (pp. 11-22). París: CNRS.

Foucault, M. (2006 [1978-79]). Seguridad, territorio y población. México: Fondo de Cultura Económica.

Garcilaso de la Vega, I. (1976 [1609]). Comentarios reales de los Incas. Tomo II. Caracas: Biblioteca Ayacucho.

Góngora, M. (1951). El Estado en el derecho indiano. Época de fundación 1492-1570. Santiago: Instituto de investigaciones histórico-culturales, Universidad de Chile.

Guaman Poma de Ayala, F. (1980 [1615/1616]). El Primer Nueva Corónica y Buen Gobierno. Caracas: Biblioteca Ayacucho.

Julien, C. (2000). Reading Inca History. Iowa: University of Iowa Press.

Julien, C. (2007). Francisco de Toledo and his campaign against the Incas. Colonial Latin American Review, 16(2), 243-272. 
Levillier, R. (1918). La Audiencia de Charcas. Correspondencia de presidentes y oidores. Tomo I. Madrid: Juan Pueyo.

Levillier, R. (1925). Gobernantes del Perú. Cartas y papales, siglo XVI. Tomo VIII. Madrid: Imprenta Juan Pueyo.

Lohmann, G. (1966). Juan de Matienzo, autor del Gobierno del Perú (su personalidad y su obra). Sevilla: Escuela de Estudios Hispano-Americanos.

Lohmann, G. (1967). Étude Préliminaire. En Gobierno del Perú (pp. V-LXIX). Lima, Paris: Institut Français d'Études Andines.

Loza, C. (2002). "Tyrannie" des Incas et "naturalisation" des Indiens. La politique de Francisco de Toledo, vice-roi du Pérou (1571-1628). Annales. Histoire, Sciences Sociales, 57(2), 375-405.

MacCormack, S. (2006). On the Wings of Time: Rome, The Incas, Spain, and Peru. Princeton: Princeton University Press.

Marzal, M. (1993). Historia de la antropología indigenista: México y Perú. Barcelona: Editorial Anthropos.

Matienzo, J. (1730?[1567]). Gobierno del Perú. MS 74, Obadian Rich Collectión, New York Public Library.

Matienzo, J. (1967 [1567]). Gobierno del Peru. (Edition et étude préliminaire par Guillermo Lohmann Villena). París - Lima: Institut Français d’ Études Andines.

Merluzzi, M. (2014 [2003]). Gobernando los Andes. Francisco de Toledo virrey del Perú (1569-1581). Lima: PUCP.

Millones, L. (1998). De Señores Naturales a Tiranos: El concepto político de los incas y sus cronistas en el siglo XVI. Latin American Literary Review, 26(52), 72-99.

Moreno Cebrián, A. (1977). El corregidor de indios y la economía peruana en el siglo XVIII. Madrid: CSIC.

Mo Romero, E. (1993). Juan de Matienzo y la perpetuidad de la encomienda. En García, P., Izard, M. y Laviña, J. (Coords.). Memoria, creación e historia (pp. 165-178). Barcelona: Ed. Universidad de Barcelona.

Mo Romero, E. (2000). Del proyecto político a la realidad: Juan de Matienzo y Francisco de Toledo. En Gutiérrez, A. (Coord.). Ciencia, Economía y Politica en Hispanoamérica Colonial (pp. 333-350). Sevilla: CSIC.
Mumford, J. R. (2011). Francisco de Toledo, admirador y émulo de la "tiranía" inca. Histórica, XXXV(2), 45-67.

Mumford, J. R. (2012). Vertical Empire; The General Resettlement of Indians in the Colonial Andes. Durham: Duke University Press.

Muro Romero, F. (1975). El tocuyrico en los pueblos de indios del Perú, según Juan de Matienzo. En Estudios sobre política indigenista española en América. Vol. 1 (pp. 306312). Valladolid: Universidad de Valladolid.

Murúa, M. (1964 [1613]). Historia General del Perú. Madrid: Instituto Gonzalo Fernández de Oviedo.

Pagden, A. (1988 [1982]). La caida del hombre natural. Madrid: Alianza.

Parra, R. (2015). La tirania del Inca. El Inca Garcilaso y la escritura politica en el Perú colonial (1568-1617). Lima: Ediciones Copé.

Pereña, L. (1982). Juan de la Peña. De Bello contra Insulanos. Intervención de España en América. Madrid: CSIC.

Pérez, I. (1988). Bartolomé de Las Casas en el Perú: 15311573. Cusco: Centro de Estudios Rurales Bartolomé de Las Casas.

Pérez, I. (1995). El Anónimo de Yucay frente a Bartolomé de Las Casas. Cusco: Centro de Estudios Regionales Andinos Bartolomé de Las Casas.

Presta, A. (2008). Matienzo, Juan de (1520-1579). En Pillsbury, J. (Ed.). Guide to Documentary Sources for Andean Studies, 1530-1900, vol. III (pp. 396-400). Norman: University of Oklahoma Press.

Pujana, L. (1977-1981). El indigenismo de Polo de Ondegardo. Boletín del Instituto Riva Agüero, 11, 109-123.

Ramos, G. (2016). Pastoral visitations: Spaces of Negotiation in Andean Indigenous Parishes. The Americas, 73(1), 39-57.

Rostworowski, M. (1988). Historia del Tawantinsuyu. Lima: IEP.

Saito, A., Rosas, C., Mumford, J., Wernke, S., Zuloaga, M. y Spalding, K. (2014). Nuevos avances en el estudio de las reducciones toledanas. Bulletin of the National Museum of Ethnology, 39(1), 123-167. 
Sarmiento de Gamboa, P. (2007 [1572]). Historia de los Incas. Madrid: Miraguano - Polifemo.

Solodkow, D. (2014). Etnógrafos Coloniales. Alteridad y escritura en la Conquista de América (siglo XVI). Madrid - Frankfurt: Iberoamericana - Vervuert.

Spalding, K. (1984). Huarochiri. An Andean Society Under Inca and Spanish Rule. Stanford: Stanford University Press.

Stern, S. (1986 [1982]). Los pueblos indigenas del Perú y el desafio de la conquista española Huamanga hasta 1640. Madrid: Alianza.

Stoler, A. (2010). Archivos coloniales y el arte de gobernar. Revista Colombiana de Antropología, 46(2), 465-496.

Toledo, F. (1921 [1582]). Memorial que D. Francisco de Toledo dio al Rey nuestro señor, del estado que dejó las cosas del Perú, después de haber sido en él virrey y capitán general trece años, que comenzaron en 1569. En Beltrán y Rózpide, R. (Ed.). Colección de las memorias o relaciones que escribieron los virreyes del Perú acerca del estado en que dejaban las cosas generales del reino. Tomo I (pp. 71-106). Madrid: Imprenta del Asilo de Huérfanos.

Vaccarella, E. (2007). Fábulas, letras and razones historiales fidedignas: the praxis of renaissance historiography in Pedro Sarmiento de Gamboa's Historia de los Incas. Colonial Latin American Review, 16(1), 93-107.

Wernke, S. (2013). Negotiated Settlements; Andean Comunities and landscapes under Inka and Spanish Colonialism. Gainesville: University Press of Florida.

Zagalski, P. (2014). La mita de Potosí: una imposición colonial invariable en un contexto de múltiples transformaciones (siglos XVI-XVII; Charcas, virreinato del Perú). Chungara. Revista de Antropología Chilena, 46(3), 375395.

Zuloaga, M. (2012). La conquista negociada, guarangas, autoridades locales e imperio en Huaylas, Perú (1532-1610). Lima: IEP - IFEA. 